Article

\title{
Brexpiprazole, a Serotonin-Dopamine Activity Modulator, Can Sensitize Glioma Stem Cells to Osimertinib, a Third-Generation EGFR-TKI, via Survivin Reduction
}

\author{
Shuhei Suzuki ${ }^{1,2}$, Masahiro Yamamoto ${ }^{1, *(1)}$, Tomomi Sanomachi ${ }^{1,2}$, Keita Togashi ${ }^{1,3}$, \\ Asuka Sugai ${ }^{1}$, Shizuka Seino ${ }^{1}$, Takashi Yoshioka ${ }^{2}$, Chifumi Kitanaka ${ }^{1,4}$ and Masashi Okada ${ }^{1}$ \\ 1 Department of Molecular Cancer Science, Yamagata University School of Medicine, 2-2-2 Iida-nishi, \\ Yamagata 990-9585, Japan \\ 2 Department of Clinical Oncology, Yamagata University School of Medicine, 2-2-2 Iida-nishi, \\ Yamagata 990-9585, Japan \\ 3 Department of Ophthalmology and Visual Sciences, Yamagata University School of Medicine, 2-2-2 \\ Iida-nishi, Yamagata 990-9585, Japan \\ 4 Research Institute for Promotion of Medical Sciences, Yamagata University Faculty of Medicine, 2-2-2 \\ Iida-nishi, Yamagata 990-9585, Japan \\ * Correspondence: masahiro@med.id.yamagata-u.ac.jp; Tel.: +81-23-628-5214
}

Received: 29 May 2019; Accepted: 3 July 2019; Published: 5 July 2019

\begin{abstract}
Glioblastoma is a primary brain tumor associated with a poor prognosis due to its high chemoresistance capacity. Cancer stem cells (CSCs) are one of the mechanisms of chemoresistance. Although therapy targeting CSCs is promising, strategies targeting CSCs remain unsuccessful. Abnormal activation of epidermal growth factor receptors (EGFRs) due to amplification, mutation, or both of the EGFR gene is common in glioblastomas. However, glioblastomas are resistant to EGFR tyrosine kinase inhibitors (EGFR-TKIs), and overcoming resistance is essential. Brexpiprazole is a new, safe serotonin-dopamine activity modulator used for schizophrenia and depression that was recently reported to have anti-CSC activity and function as a chemosensitizer. Here, we examined its chemosensitization effects on osimertinib, a third-generation EGFR-TKI with an excellent safety profile, in glioma stem cells (GSCs), which are CSCs of glioblastoma. Brexpiprazole treatment sensitized GSCs to osimertinib and reduced the expression of survivin, an antiapoptotic factor, and the pharmacological and genetic inhibition of survivin mimicked the effects of brexpiprazole. Moreover, co-treatment of brexpiprazole and osimertinib suppressed tumor growth more efficiently than either drug alone without notable toxicity in vivo. This suggests that the combination of brexpiprazole and osimertinib is a potential therapeutic strategy for glioblastoma by chemosensitizing GSCs through the downregulation of survivin expression.
\end{abstract}

Keywords: glioma stem cell; glioblastoma; brexpiprazole; osimertinib; survivin; xenograft

\section{Introduction}

Glioblastoma is the most common primary brain tumor, accounting for $60 \%$ to $70 \%$ of glial brain tumors [1,2]. The outcome of glioblastoma is poor due to its highly infiltrative growth and high chemoresistance to therapeutic agents such as temozolomide [3,4]. Cancer stem cells (CSCs), which have high tumor initiation capacity and are resistant to chemotherapeutic reagents, play a role in chemoresistance [5-8]. Thus, the development of drugs eradicating glioma stem cells (GSCs), CSCs of glioblastoma, is important for the treatment of glioblastoma. However, the number of drugs used 
for glioblastoma is limited because drugs that poorly penetrate the blood-brain barrier (BBB) are not effective for glioblastoma [9].

The EGFR gene is amplified in $40 \%$ of glioblastomas [10,11]. Approximately $50 \%$ of $E G F R$-amplified glioblastomas express epidermal growth factor receptor (EGFR) variant III (EGFRvIII) resulting from the in-frame deletion of exons 2-7. EGFRvIII lacks a major part of the extracellular domain and is constitutively active [12,13]; therefore, EGFRvIII plays a role in the progression of glioblastoma [10,11,14]. Thus, inhibitors of EGFR are considered as a therapeutic option for glioblastoma [15-17]. However, in clinical trials with epidermal growth factor receptor tyrosine kinase inhibitors (EGFR-TKIs), such as gefitinib, erlotinib, and dacomitinib, clinical benefits were limited or absent [18-21]. Furthermore, the reason for resistance to EGFR-TKIs in glioblastoma remains unknown [15,19].

Osimertinib is an oral, third generation, irreversible EGFR-TKI. Osimertinib was developed to treat the "gatekeeper" EGFR mutation, which replaces a threonine at codon 790 with a methionine (T790M) that is acquired in approximately $50 \%$ of cases of non-small cell lung cancer (NSCLC) during treatment with first-generation TKIs [22,23]. Osimertinib is used as second-line chemotherapy for patients with metastatic NSCLC harboring T790M EGFR mutation who have disease progression during or after therapy with an EGFR-TKI. In a clinical trial, the efficacy and safety of osimertinib were superior to those of standard EGFR-TKIs in the first-line treatment of NSCLC, suggesting that osimertinib can be used for first-line chemotherapy [24]. Moreover, osimertinib had a better toxicity profile than standard EGFR-TKIs in clinical studies [23,24]. It can also penetrate the blood-brain barrier more efficiently than other EGFR-TKIs [25], and clinical trials demonstrated osimertinib to be more effective for NSCLC with brain metastasis than standard therapy $[23,24,26]$. Therefore, osimertinib is a potential candidate drug for the treatment of glioblastoma. However, the effects of osimertinib on glioblastoma have not been examined, and there are concerns that glioblastoma might be resistant to osimertinib, similar to other EGFR-TKIs.

Brexpiprazole is a new antipsychotic drug for depression and schizophrenia. Brexpiprazole was developed as a drug chemically and pharmacologically related to aripiprazole, a serotonin-dopamine activity modulator. Although brexpiprazole has similar pharmacological activity to aripiprazole, brexpiprazole has a better safety profile due to its lower intrinsic activity at the dopaminergic D2 and D3 receptors [27-29]. We previously reported that aripiprazole has anticancer effects and acts as a chemosensitizer in CSCs of NSCLC and pancreatic cancer [30]. Moreover, we recently revealed that brexpiprazole exhibits anticancer activity against several types of cancer, including glioblastoma, and chemosensitizes CSCs of pancreatic cancer and NSCLC to gemcitabine and 5-fluorouracil by downregulating survivin, an antiapoptotic protein [31]. Suppression of survivin is involved in the resistance to first-generation EGFR-TKIs of NSCLC: erlotinib and gefitinib [32-34]. These observations suggest that brexpiprazole acts as a chemosensitizer of EGFR-TKIs. Furthermore, as there are no clinically approved drugs targeting survivin, from the standpoint of clinical application, it is of interest to explore whether brexpiprazole, a clinically available and safe drug, chemosensitizes GSCs to osimertinib. Thus, in this study, we examined the combinational effects of osimertinib and brexpiprazole on GSCs in vitro and in vivo and addressed the mechanism of the combinational effects.

\section{Results}

\subsection{Brexpiprazole Sensitizes GSCs to Osimertinib}

As previously reported, glioblastoma tumor-initiating cells have varying degrees of responsiveness to EGFR-TKIs [35]. We first examined the responsiveness of different types of GSCs to osimertinib using a representative GSC line, A172GS, and patient-derived GSC lines: GS-Y01, GS-NCC01, and GS-Y03 (Figure 1a,b). Regarding osimertinib treatment, GS-NCC01 exhibited low responses, A172GS and GS-Y01 exhibited moderate responses, and GS-Y03 exhibited high responses, indicating different sensitivities to osimertinib by these GSCs. As the presence of EGFRvIII mutations may affect the sensitivity of osimertinib, we examined the expression of EGFRvIII in these cells. A172GS 
and GS-NCC01 cells expressed EGFRvIII but GS-Y01 and GS-Y03 cells did not, suggesting no correlation between EGFRvIII expression and osimertinib sensitivity (Figure S1). Next, we examined whether brexpiprazole increases the responsiveness to osimertinib of the GSCs. The combination of brexpiprazole with osimertinib reduced the viable cell number (Figure 1a) and increased cell death (Figure 1b) in the GSCs irrespective of their sensitivity to osimertinib. As we previously reported that brexpiprazole reduces the expression of survivin, a chemoresistant factor of cancer cells [30], in CSCs from different cancers, including GS-Y03 cells [31], we assessed the alteration of survivin expression by brexpiprazole in these cells. Brexpiprazole reduced the expression of survivin in the GSCs (Figure 1c). Furthermore, we examined whether brexpiprazole affects downstream signals of EGFR. However, brexpiprazole treatment did not cause consistent changes in the expression levels of $\mathrm{p}$-AKT, $\mathrm{p}$-mTOR, and p-ERK among the cell lines examined (Figure 1d).

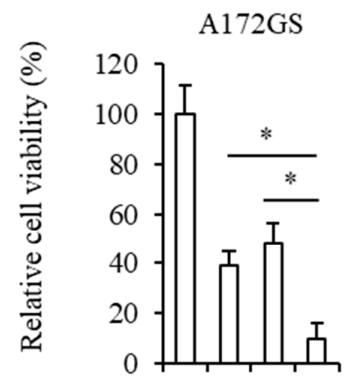

Osimertinib Brexpiprazole

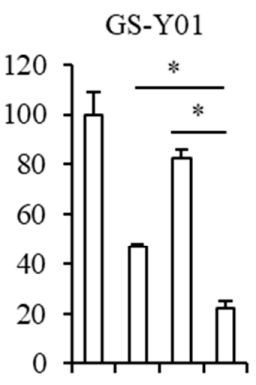

$-+-+$

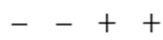

(a) GS-Y01
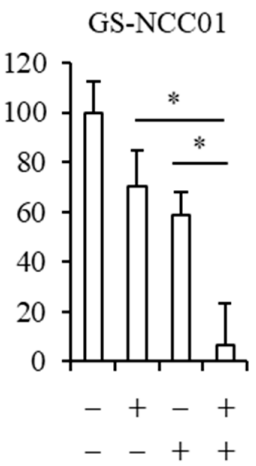

GS-Y03

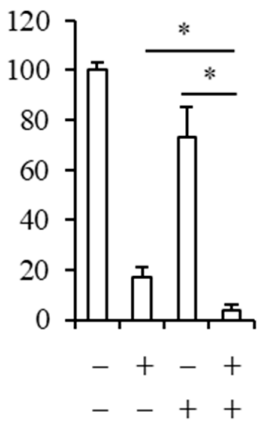

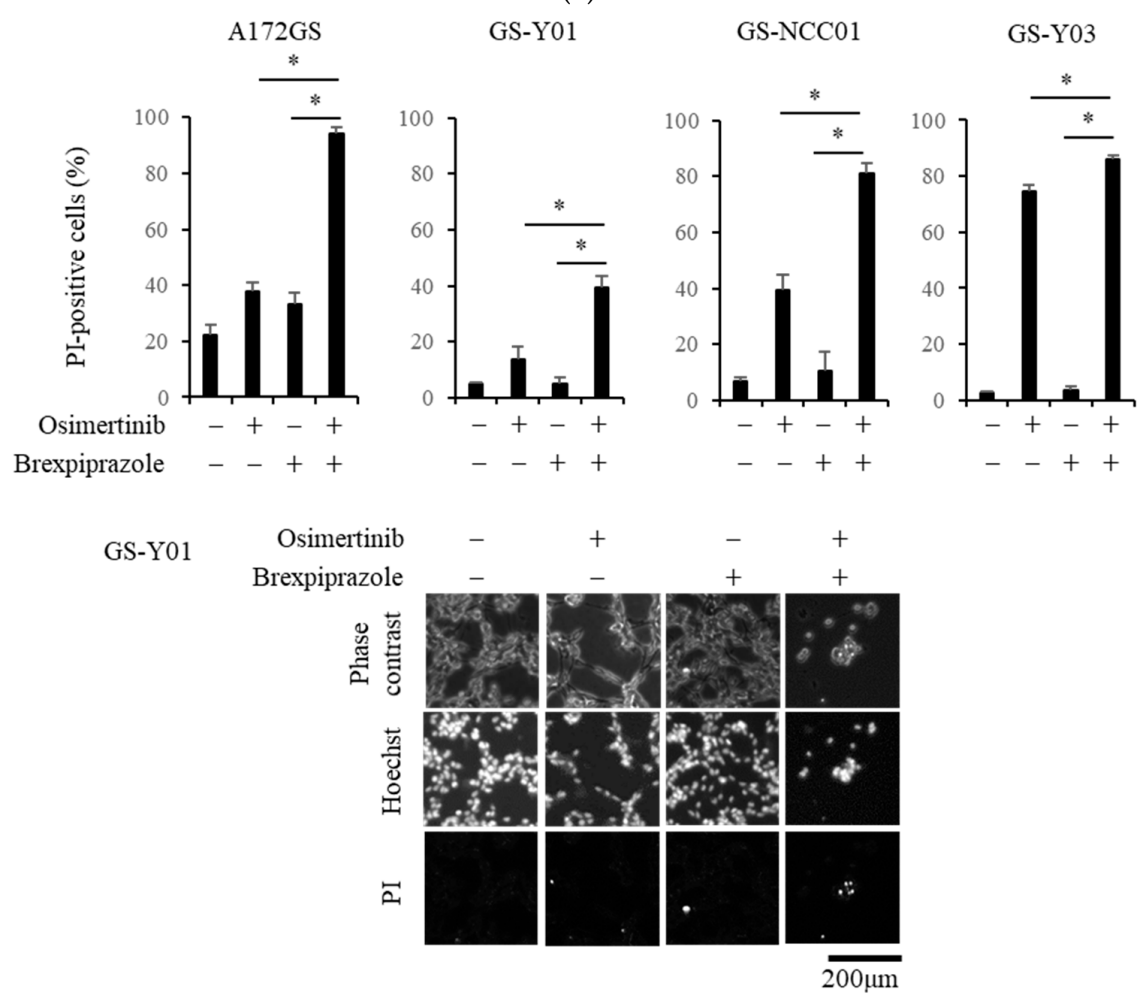

(b)

Figure 1. Cont. 


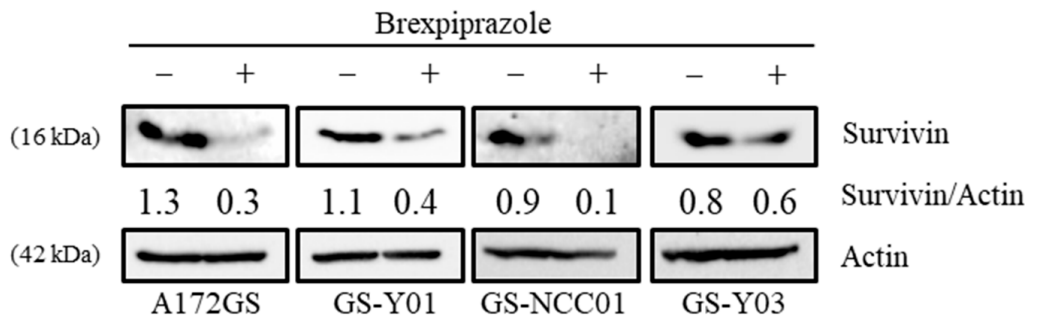

(c)

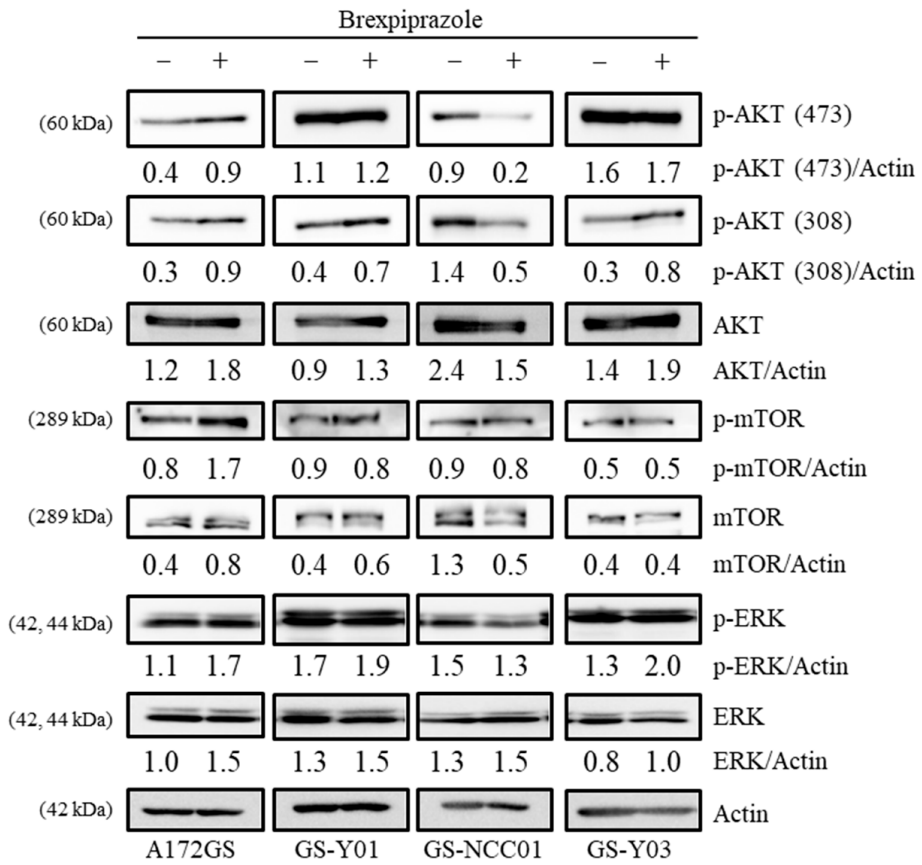

(d)

Figure 1. The effects of osimertinib and brexpiprazole combination treatment on glioma stem cell (GSC) proliferation and survivin expression: GSCs (A172GS, GS-Y01, GS-NCC01, and GS-Y03) were treated with or without $1.5 \mu \mathrm{M}$ of osimertinib and with or without $3 \mu \mathrm{M}$ of brexpiprazole for 3 days and were then subjected to several analyses. (a) The cells were subjected to cell viability assay using WST-8. Values represent means + SD from quadruplicate samples of a representative experiment repeated with similar results. ${ }^{*} p<0.05$. (b) The cells were subjected to cell death assay using Hoechst 33342 (Hoechst) and propidium iodide (PI). The upper graphs show the proportion of dead cells as means + $\mathrm{SD}$ from triplicate samples of a representative experiment repeated with similar results. ${ }^{*} p<0.05$. The lower panels show representative phase contrast images, Hoechst-positive images (total cells), and PI-positive cells (dead cells) among GS-Y01 cells. Scale bar: $200 \mu \mathrm{m}$. (c,d) The cells were subjected to immunoblot analysis for survivin, p-AKT, AKT, p-mTOR, mTOR, p-ERK, and ERK.

\subsection{Pharmacological Inhibition of Survivin Sensitizes GSCs to Osimertinib}

As recent studies revealed that EGFR-TKI resistance is partially due to the expression of survivin, a representative antiapoptotic molecule [32-34], we evaluated the effects of the pharmacological inhibition of survivin on two representative GSC lines, A172GS and GS-Y01, which are moderately resistant to osimertinib using YM155, a pharmacological inhibitor of survivin [36,37]. YM155 treatment reduced the expression of survivin (Figure 2a). Next, we examined whether YM155 treatment mimics the effects of brexpiprazole as a sensitizer to osimertinib. YM155 treatment sensitized the GSCs to osimertinib to a similar degree as brexpiprazole (Figure 2b), suggesting the involvement of survivin in the mechanism of osimertinib sensitization by brexpiprazole. 


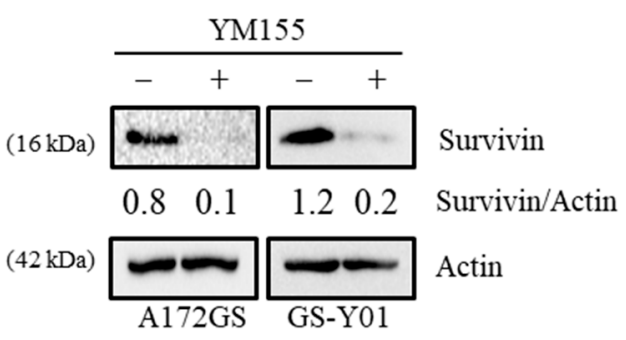

(a)
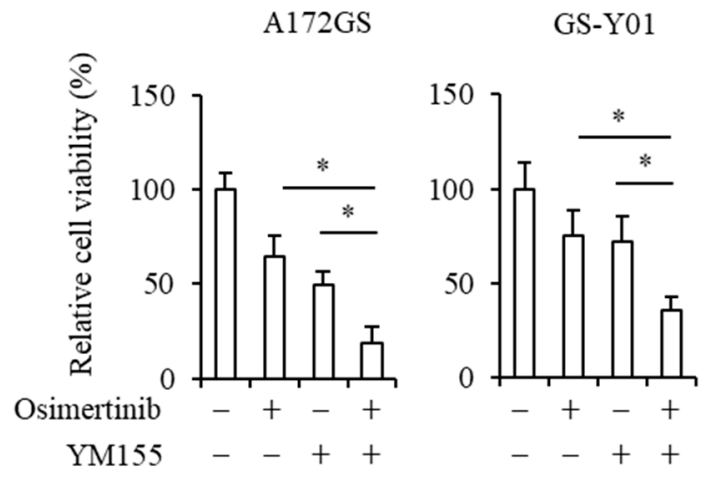

(b)

Figure 2. Pharmacological inhibition of survivin by YM155-induced sensitization of GSCs to osimertinib: The indicated GSCs were treated with or without $10 \mathrm{nM}$ of YM155 and with or without $1.5 \mu \mathrm{M}$ of osimertinib for 3 days. (a) The cells (with or without YM155 only) were subjected to immunoblot analysis for survivin protein expression. (b) The cells were then subjected to cell viability assay using WST-8. Values represent means + SD from quadruplicate samples of a representative experiment repeated with similar results. ${ }^{*} p<0.05$.

\subsection{Genetic Inhibition of Survivin Mimics Brexpiprazole Treatment}

To exclude the possibility of off-target effects of brexpiprazole and YM155 on mechanisms other than survivin, we next examined the effects of genetic inhibition of survivin on the responsiveness to osimertinib by the GSCs using siRNA. After introducing two different siRNAs against survivin, siSurvivin\#2 and siSurvivin\#3, the expression of survivin decreased (Figure 3a). On the other hand, a non-targeting siRNA (siControl) did not cause a decrease in survivin expression. In the cells with siRNAs against survivin, osimertinib resistance was attenuated (Figure $3 b$ ). Therefore, survivin expression is necessary for osimertinib resistance in GSCs.

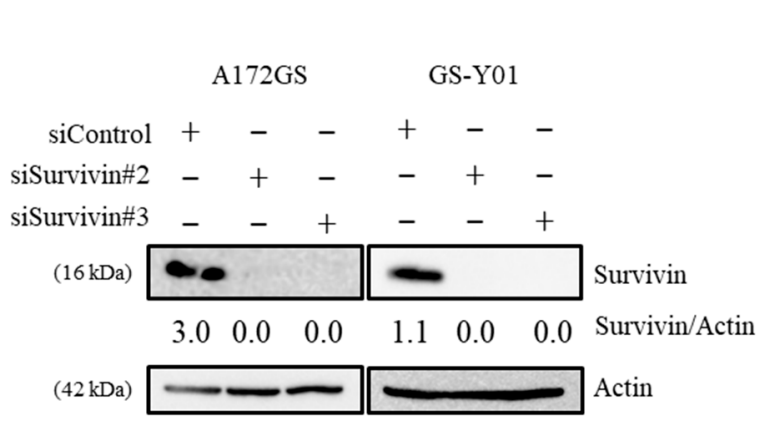

(a)

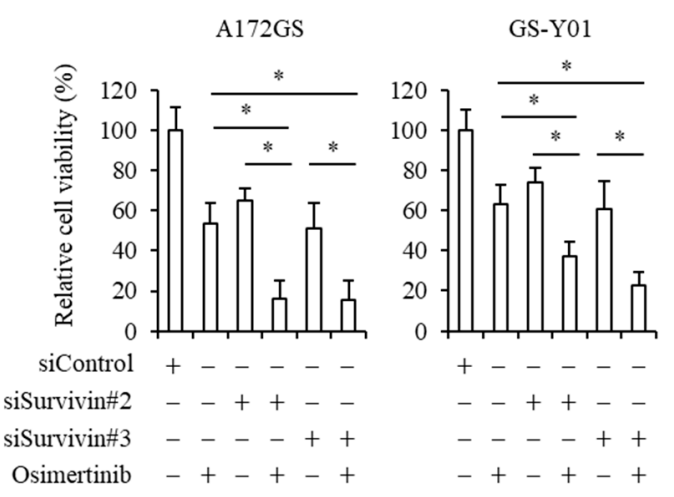

(b)

Figure 3. siRNA-mediated knockdown of survivin sensitizes GSCs to osimertinib: The indicated GSCs were transfected with a non-targeting siRNA (siControl) or either of the siRNAs against survivin (siSurvivin\#2 or siSurvivin\#3) for 3 days. (a) The cells were subjected to immunoblot analysis for survivin protein expression. (b) Then, the transfected cells were treated with or without $1.5 \mu \mathrm{M}$ of osimertinib for 3 days, and the cells were subjected to cell viability assay using WST-8. Values represent means + SD from quadruplicate samples of a representative experiment repeated with similar results. * $p<0.05$. 


\subsection{Brexpiprazole Sensitizes GSCs to Osimertinib in Vivo.}

Survivin inhibition effectively attenuated the resistance to osimertinib of the GSCs in vitro. To adapt the combination of brexpiprazole and osimertinib to clinical settings, we examined the efficacy of the combination in a preclinical mouse xenograft model. GS-Y03 cells were implanted intracranially into nude mice, and the mice were treated with osimertinib, brexpiprazole, their combination, or solvent control. As a result, the mice treated with the combination of osimertinib and brexpiprazole survived significantly longer than those treated with either osimertinib or brexpiprazole (Figure 4a). Administration of brexpiprazole and osimertinib did not reduce the body weight of the mice (Figure $4 \mathrm{~b}$ ). No notable adverse effects were observed in the mice.

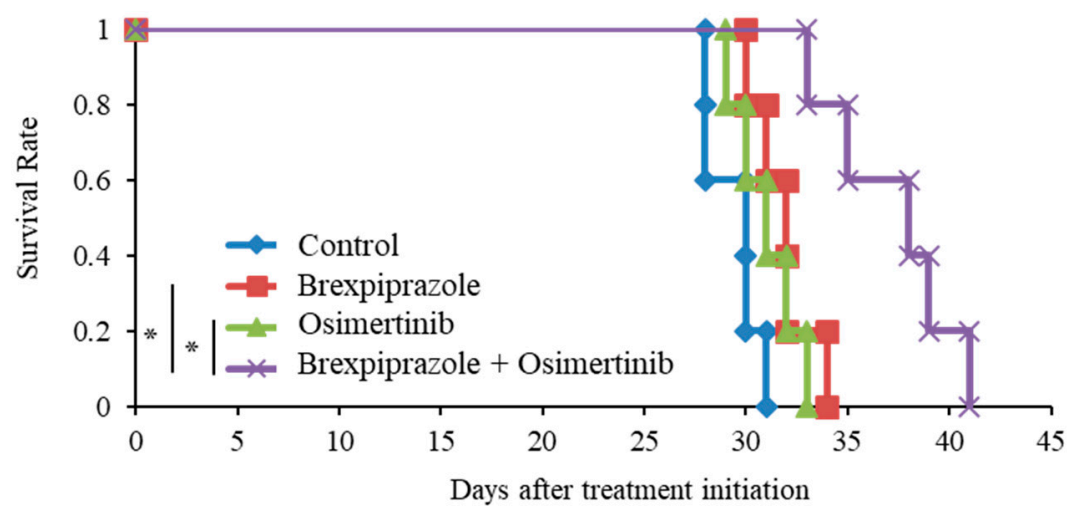

(a)
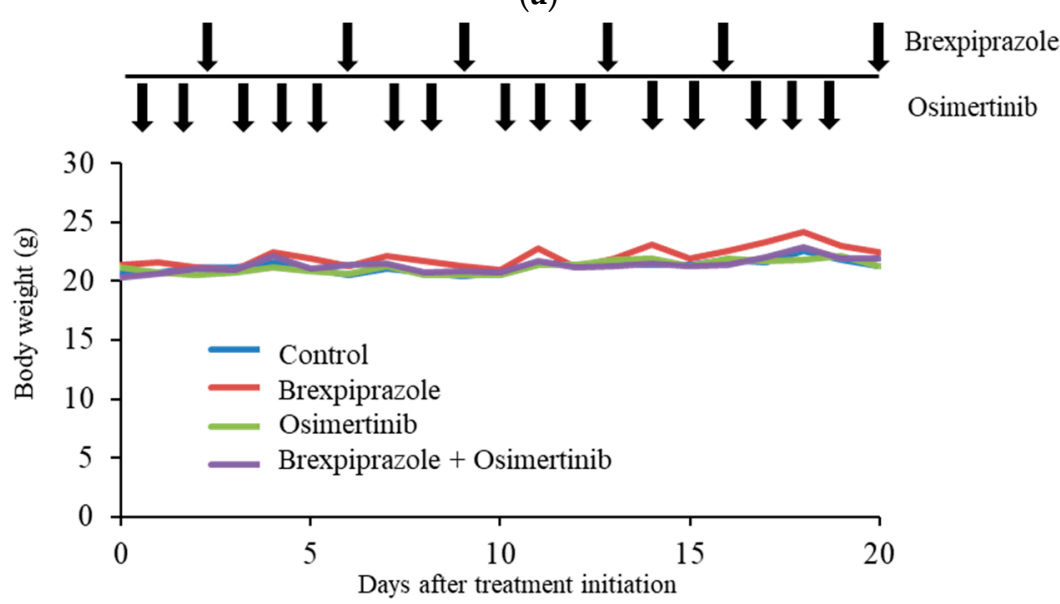

(b)

Figure 4. Systemic combination administration of brexpiprazole and osimertinib has anticancer stem effects in vivo. After patient-derived GSCs (GS-Y03, $1 \times 10^{4}$ cells) were intracranially injected to the left-brain hemisphere of nude mice, the indicated drugs ( $3 \mathrm{mg} / \mathrm{kg}$ of brexpiprazole twice a week and $5 \mathrm{mg} / \mathrm{kg}$ of osimertinib 5 times a week) were orally administered after 2 days. (a) Survival was evaluated by a Kaplan-Meier analysis. (b) The body weights of the mice (means with SD) were presented. Arrows indicate the treatment schedule. ${ }^{*} p<0.05$.

\section{Discussion}

Glioblastoma is one of the most intractable malignancies. Although surgery followed by radiation or chemotherapy improves the prognosis, the effectiveness of these therapies is limited, resulting in a median survival of only 12-15 months [3,38-40]. One of the reasons for the ineffectiveness of the therapies is GSCs. GSCs have a high tumor initiation capacity and are resistant to chemotherapy and radiotherapy [41]. Therefore, it is essential to eradicate GSCs to cure glioblastomas. As the EGFR gene is amplified in $40 \%$ of primary glioblastomas $[10,11]$, therapy targeting EGFR was considered 
promising. However, the results of clinical trials with first- and second-generation EGFR-TKIs for glioblastoma were disappointing [18-20]. Osimertinib, an oral third-generation EGFR-TKI, penetrates the BBB more effectively [25] and has a better safety profile than other EGFR-TKIs [23,24]. A clinical trial with osimertinib on glioblastoma is still ongoing (NCATS 1-UH2-TR001370-01), and the effectiveness of osimertinib remains unknown, even for in vitro studies. In this study, we found that the sensitivity to osimertinib of GSCs was different among the four types of GSCs examined. Of the four, three types of GSCs were resistant and only one type was sensitive to osimertinib, demonstrating that GSCs are often resistant to osimertinib. Brexpiprazole was developed as a new serotonin-dopamine activity modulator with an improved safety profile to succeed aripiprazole. We recently reported that brexpiprazole acts as a chemosensitizer to gemcitabine and 5-fluorouracil in CSCs of pancreatic cancer and NSCLC [31]. In this study, we revealed that brexpiprazole sensitized the GSCs to osimertinib regardless of their sensitivity to osimertinib in vitro. Moreover, brexpiprazole sensitized the osimertinib-resistant GSCs to osimertinib in a preclinical mouse model.

The mechanisms of resistance to EGFR-TKI in glioblastomas remain obscure [18-21]. The pharmacological efficacy of gefitinib and erlotinib, first-generation EGFR-TKIs, mainly depends on activation mutation in exons 19 and 21 of the tyrosine kinase domain. The absence of these mutations in glioblastoma partially explains the resistance to gefitinib and erlotinib [15,42]. Another possible mechanism is an alternative activating signal that compensates for the inactivation of EGFR signaling by EGFR-TKIs [43]. It was previously reported that the absence of EGFRvIII and loss of PTEN are partial determinants of resistance [15,44]. Inhibition of mTOR, a downstream molecule of the PI3 kinase/PTEN/AKT pathway, promoted the response of glioma cells to EGFR-TKIs in vitro [45,46]. However, phase II clinical trials with relapsed glioblastoma patients did not support the correlation between the responsiveness to erlotinib and the expression of EGFRvIII and PTEN [47,48]. Moreover, the combination of sirolimus, an inhibitor of mTOR, and EGFR-TKIs did not improve the responsiveness in patients with recurrent glioblastomas [49]. Alternatively, inhibition of EGFR by erlotinib in EGFRvIII-expressing U87 glioblastoma cells may increase the expression of PDGFR $\beta$, which compensates for signaling inhibited by erlotinib. Co-inhibition of PDGFR $\beta$ by AG1295, an inhibitor of PDGFR, with erlotinib effectively suppressed tumor growth [50]. Erlotinib upregulates promyelocytic leukemia (PML) protein, which is a negative regulator of AKT-mTOR signaling, to promote resistance to erlotinib, and treatment with a PML inhibitor chemosensitizes glioblastoma cells to erlotinib and an mTOR inhibitor, suggesting the clinical relevance of the combination of PML-targeting drugs and erlotinib [51]. Screening with an shRNA library using glioblastoma cells revealed that the combined inhibition of dopamine D2 receptors and EGFR-TKI leads to synergistic tumoricidal activity through suppression of the MAP kinase pathway [52]. Although the mechanism they suggested is different from ours, those data support our findings that brexpiprazole sensitized GSCs to osimertinib.

We recently reported that brexpiprazole reduces the expression of survivin and chemosensitizes pancreatic cancer and NSCLC to gemcitabine and 5-fluorouracil [31]. However, whether brexpiprazole chemosensitizes GSCs to EGFR-TKIs via the downregulation of survivin was unclear. In this study, both the genetic inhibition of survivin by siRNA and the pharmacological inhibition by YM155, a suppressor of survivin, chemosensitized GSCs to osimertinib. Although our data do not exclude the possibility of involvement of mechanisms other than survivin, they do suggest that downregulation of survivin is, at least in part, one of the major mechanisms of chemosensitization by brexpiprazole. Consistent with our data, survivin is involved in resistance against EGFR-TKIs in NSCLCs [32-34]. Clinical benefits of YM155 are not proven in clinical trials [53-55], and YM155 is not approved worldwide. As brexpiprazole is FDA-approved and applicable for clinical translation with a detailed safety profile $[28,56,57]$, it is a good candidate drug to chemosensitize GSCs to EGFR-TKIs by downregulating the expression of survivin.

In a clinical trial, serious adverse events of grade 3 or higher were reported in fewer patients administered osimertinib than in those receiving standard EGFR-TKIs ( $34 \%$ vs. $45 \%)$, suggesting the better safety profile of osimertinib [24]. Brexpiprazole was developed to succeed aripiprazole, a 
serotonin-dopamine activity modulator. Compared with aripiprazole, brexpiprazole was reported to cause fewer adverse effects; akathisia and insomnia occur 50\% less frequently than with aripiprazole [28,58,59]. Of note, the combination of brexpiprazole and osimertinib exhibited therapeutic effects in mice but did not cause any notable adverse effects, including alteration of body weight, demonstrating the clinical relevance of our animal experiments.

\section{Materials and Methods}

\subsection{Antibodies and Reagents}

Anti-survivin (\#2808), anti-p-AKT (Ser473 \#9271, Thr308 \#9275), anti-AKT (\#9272), anti-p-mTOR (\#2974), anti-mTOR (\#2972), anti-p-ERK (\#9101), anti-ERK (\#4695), and anti-EGFR (\#4267) antibodies were purchased from Cell Signaling Technology, Inc. (Beverly, MA, USA). Anti- $\beta$-actin (A1978) antibody was from Sigma (St. Louis, MO, USA). Osimertinib and YM155 were purchased from Chemscene LLC. (Monmouth Junction, NJ, USA), and dissolved in dimethyl sulfoxide (DMSO) to $10 \mathrm{mM}$ and $20 \mu \mathrm{M}$, respectively, as stock solutions. Brexpiprazole was from Cayman Chemical Company (Ann Arbor, MI, USA) and was dissolved in DMSO to $10 \mathrm{mM}$ as a stock solution.

\subsection{Cell Culture}

Patient-derived GSCs used in this study (GS-Y01, GS-NCC01, and GS-Y03) were established and cultured as previously described [60,61], and the A172GS GSC line was also established and cultured as previously described [62]. In brief, cells were cultured on collagen-I-coated dishes (IWAKI, Tokyo, Japan) in stem cell culture medium [60] (DMEM/F12 medium with 1\% B27 (Thermo Fisher Scientific, Waltham, MA, USA), 20 ng/mL of EGF and FGF2 (Peprotech, Inc., Rocky Hill, NJ, USA), D-(+)-glucose (final concentration of $26.2 \mathrm{Mm}$ ), L-glutamine (final concentration of $4.5 \mathrm{mM}$ ), 100 units/mL of penicillin, and $100 \mu \mathrm{g} / \mathrm{mL}$ of streptomycin). This stem cell culture medium was replaced every 3 days, and EGF and FGF2 were added to the medium every day. 293T cells were cultured in DMEM supplemented with $10 \%$ fetal bovine serum, 100 units/mL of penicillin, and $100 \mu \mathrm{g} / \mathrm{mL}$ of streptomycin.

\subsection{Cell Viability and Cell Death Assays}

Cell viability assays were performed as previously described [63]. In brief, cell viability was assessed by the tetrazolium salt reduction method using WST-8 (Cell Counting Kit-8; Dojindo Laboratories, Kumamoto, Japan) according to the manufacturer's protocol. Cells (500-1000 cells/well) plated in 96-well collagen I-coated plates were treated with drugs the next day for 3 days. WST-8 reagent was then added, and the cells were incubated for $1-3 \mathrm{~h}$ at $37^{\circ} \mathrm{C}$. Absorbance at $450 \mathrm{~nm}$ was measured using a microplate reader (Model 680, Bio-Rad, Hercules, CA, USA). Relative cell viability was calculated as a percentage of the absorbance of treated samples relative to that of control samples. Cell viability assays were performed in four replicates. Alternatively, cells were incubated in situ with propidium iodide (PI, $1 \mu \mathrm{g} / \mathrm{mL})$ and Hoechst 33,342 $(10 \mu \mathrm{g} / \mathrm{mL})$ for $5 \mathrm{~min}$ at $37^{\circ} \mathrm{C}$ in the $\mathrm{CO}_{2}$ incubator to stain dead cells and the cell nuclei, respectively. Then, the numbers of PI- and Hoechst-stained cells were counted using a fluorescence microscope (CKX41; Olympus, Tokyo, Japan), and the percentage of PI-stained cells (dead cells) against Hoechst-stained cells (total cells) was calculated [64].

\subsection{Immunoblot Analysis}

Cells were washed with ice-cold PBS and lysed in RIPA buffer (10 mM Tris- $\mathrm{HCl}$ (pH 7.4), 0.1\% SDS, $0.1 \%$ sodium deoxycholate, $1 \% \mathrm{NP}-40,150 \mathrm{mM} \mathrm{NaCl}, 1 \mathrm{mM}$ EDTA, $1.5 \mathrm{mM} \mathrm{Na}_{3} \mathrm{VO}_{4}, 10 \mathrm{mM} \mathrm{NaF}, 10 \mathrm{mM}$ sodium pyrophosphate, $10 \mathrm{mM}$ sodium $\beta$-glycerophosphate. and $1 \%$ protease inhibitor cocktail set III (Wako Pure Chemical Industries, Ltd, Osaka, Japan)). After centrifugation for 10 minutes at $14,000 \times g$ at $4{ }^{\circ} \mathrm{C}$, the supernatants were harvested as the cell lysates and the protein concentration of the cell lysates was measured using the BCA protein assay kit (Thermo Fisher Scientific). Cell lysates containing equal amounts of protein were separated by SDS-PAGE and transferred to polyvinylidene difluoride 
membranes. The membranes were probed with primary antibodies and then with an appropriate HRP-conjugated secondary antibody according to the manufacturer's protocol. Immunoreactive bands were visualized by Immobilon Western Chemiluminescent HRP Substrate (Merck Millipore, Billerica, MA, USA) and detected semi-quantitatively using a ChemiDoc Touch Imaging System (Bio-Rad). The relative density of immunoreactive bands was analyzed by densitometry using ImageJ 1.52a software (National Institutes of Health, Bethesda, MD, USA). The original immunoblot pictures were shown in Figure S2.

\subsection{Gene Silencing with siRNA.}

Two siRNAs against human survivin (BIRC5,\#2; HSS 179404 and \#3; HSS 179405) and Medium GC Duplex \#2 of Stealth RNAi ${ }^{\mathrm{TM}}$ siRNA Negative Control Duplexes (non-targeting control) were purchased from Thermo Fisher Scientific. Cells were transiently transfected with RNAs using Lipofectamine RNAiMAX $^{\mathrm{TM}}$ (Thermo Fisher Scientific) according to the manufacturer's directions.

\subsection{Mouse Study}

After the nude mice (7-week-old male BALB/cAJcl-nu/nu mice (CLEA Japan, Inc., Tokyo, Japan)) were anesthetized by subcutaneous injection of $25 \mathrm{mg} / \mathrm{kg}$ of midazolam, $5 \mathrm{mg} / \mathrm{kg}$ of medetomidine, and $25 \mathrm{mg} / \mathrm{kg}$ of butorphanol, GS-Y03 $\left(1 \times 10^{4}\right.$ cells diluted in $10 \mu \mathrm{L}$ of DMEM/F12 medium), patient-derived GSCs, were stereotactically injected into the left cerebral hemisphere at a depth of $3 \mathrm{~mm}$, as previously described [62]. Two days after intracranial implantation, brexpiprazole was administered by oral gavage twice a week (dose of $3 \mathrm{mg} / \mathrm{kg}$, final volume $100 \mu \mathrm{L}$ in DMSO) and osimertinib was administered by oral gavage 5 times a week (dose of $5 \mathrm{mg} / \mathrm{kg}$, final volume $100 \mu \mathrm{L}$ in DMSO). Control mice were administered the same volume of DMSO. Five mice were assigned to each group. All mice were monitored for their general health status. The termination criteria were marked weight loss of greater than $20 \%$ of that at the initiation of the experiment or apparent health problems such as inability to access food and water. The experiment was approved by the Animal Research Committee of Yamagata University (30027, 14 March 2018).

\subsection{Transfection of Plasmid}

The plasmid pT3.5-CMV-EGFRvIII was a gift from John Ohlfest (Addgene plasmid \#20280). The plasmid was transfected into 293T cells by using Lipofectamine 2000 (Thermo Fischer Scientific) according to the manufacturer's instructions. The cell lysate from the transfected cells was used as a positive control for EGFRvIII.

\subsection{Statistical Analysis}

Results are expressed as the means and standard deviation (SD). The differences were compared by the two-tailed $t$-test. The survival curve was evaluated by the Kaplan-Meier method and analyzed using the log-rank test. $p$-values $<0.05$ were considered significant and indicated with asterisks.

\section{Conclusions}

In conclusion, brexpiprazole, a safe and newly-developed antipsychotic drug, sensitized GSCs to osimertinib in vitro and in vivo via survivin downregulation.

Supplementary Materials: The following is available online at http://www.mdpi.com/2072-6694/11/7/947/s1: Figure S1: Expression of EGFR in GSCs: The expression of EGFR in the GSCs was examined by immunoblot analysis. The expression of EGFRvIII was evaluated by comparing with sample of 293T cells transfected with a plasmid for EGFRvIII overexpression. Figure S2: Original immunoblotting membranes.

Author Contributions: Conceptualization, S.S. (Shuhei Suzuki), M.Y., C.K., and M.O.; methodology, S.S. (Shuhei Suzuki), M.Y., and A.S.; software, S.S. (Shuhei Suzuki) and M.Y.; validation, S.S. (Shuhei Suzuki) and M.Y.; resources, S.S. (Shuhei Suzuki), M.Y., T.S., C.K., and M.O.; data curation, S.S. (Shuhei Suzuki) and M.Y.; writing-original draft preparation, S.S. (Shuhei Suzuki) and M.Y.; writing—review and editing, T.S., K.T., A.S., S.S. (Shizuka Seino), 
T.Y., and M.O.; supervision, M.Y., C.K., and M.O.; project administration, C.K.; funding acquisition, S.S. (Shuhei Suzuki), M.Y., T.S., C.K., and M.O.

Funding: This study was funded by Grants-in-Aid for Scientific Research, for Challenging Exploratory Research, and for Young Scientists from the Ministry of Education, Culture, Sports, Science, and Technology of Japan.

Acknowledgments: This work was supported by Grants-in-Aid for Scientific Research, for Challenging Exploratory Research, and for Young Scientists from the Ministry of Education, Culture, Sports, Science, and Technology of Japan.

Conflicts of Interest: The authors declare no conflicts of interest.

\section{References}

1. Omuro, A.; DeAngelis, L.M. Glioblastoma and other malignant gliomas: A clinical review. JAMA 2013, 310, 1842-1850. [CrossRef] [PubMed]

2. Thomas, A.A.; Brennan, C.W.; DeAngelis, L.M.; Omuro, A.M. Emerging therapies for glioblastoma. JAMA Neurol. 2014, 71, 1437-1444. [CrossRef]

3. Stupp, R.; Mason, W.P.; van den Bent, M.J.; Weller, M.; Fisher, B.; Taphoorn, M.J.; Belanger, K.; Brandes, A.A.; Marosi, C.; Bogdahn, U.; et al. Radiotherapy plus concomitant and adjuvant temozolomide for glioblastoma. N. Engl. J. Med. 2005, 352, 987-996. [CrossRef] [PubMed]

4. Chamberlain, M.C. Temozolomide: Therapeutic limitations in the treatment of adult high-grade gliomas. Expert Rev. Neurother. 2010, 10, 1537-1544. [CrossRef]

5. Beck, B.; Blanpain, C. Unravelling cancer stem cell potential. Nat. Rev. Cancer 2013, 13, 727-738. [CrossRef] [PubMed]

6. Maugeri-Sacca, M.; Vigneri, P.; De Maria, R. Cancer stem cells and chemosensitivity. Clin. Cancer Res. 2011, 17, 4942-4947. [CrossRef]

7. Chen, R.; Nishimura, M.C.; Bumbaca, S.M.; Kharbanda, S.; Forrest, W.F.; Kasman, I.M.; Greve, J.M.; Soriano, R.H.; Gilmour, L.L.; Rivers, C.S.; et al. A hierarchy of self-renewing tumor-initiating cell types in glioblastoma. Cancer Cell 2010, 17, 362-375. [CrossRef] [PubMed]

8. Beier, D.; Schulz, J.B.; Beier, C.P. Chemoresistance of glioblastoma cancer stem cells-Much more complex than expected. Mol. Cancer 2011, 10, 128. [CrossRef] [PubMed]

9. Sarkaria, J.N.; Hu, L.S.; Parney, I.F.; Pafundi, D.H.; Brinkmann, D.H.; Laack, N.N.; Giannini, C.; Burns, T.C.; Kizilbash, S.H.; Laramy, J.K.; et al. Is the blood-brain barrier really disrupted in all glioblastomas? A critical assessment of existing clinical data. Neuro-Oncology 2018, 20, 184-191. [CrossRef]

10. Libermann, T.A.; Nusbaum, H.R.; Razon, N.; Kris, R.; Lax, I.; Soreq, H.; Whittle, N.; Waterfield, M.D.; Ullrich, A.; Schlessinger, J. Amplification, enhanced expression and possible rearrangement of EGF receptor gene in primary human brain tumours of glial origin. Nature 1985, 313, 144-147. [CrossRef]

11. Wong, A.J.; Bigner, S.H.; Bigner, D.D.; Kinzler, K.W.; Hamilton, S.R.; Vogelstein, B. Increased expression of the epidermal growth factor receptor gene in malignant gliomas is invariably associated with gene amplification. Proc. Natl. Acad. Sci. USA 1987, 84, 6899-6903. [CrossRef] [PubMed]

12. Huang, P.H.; Xu, A.M.; White, F.M. Oncogenic EGFR signaling networks in glioma. Sci. Signal. 2009, 2, re6. [CrossRef] [PubMed]

13. Hatanpaa, K.J.; Burma, S.; Zhao, D.; Habib, A.A. Epidermal growth factor receptor in glioma: Signal transduction, neuropathology, imaging, and radioresistance. Neoplasia 2010, 12, 675-684. [CrossRef] [PubMed]

14. Soeda, A.; Lathia, J.; Williams, B.J.; Wu, Q.; Gallagher, J.; Androutsellis-Theotokis, A.; Giles, A.J.; Yang, C.; Zhuang, Z.; Gilbert, M.R.; et al. The p38 signaling pathway mediates quiescence of glioma stem cells by regulating epidermal growth factor receptor trafficking. Oncotarget 2017, 8, 33316-33328. [CrossRef] [PubMed]

15. Mellinghoff, I.K.; Wang, M.Y.; Vivanco, I.; Haas-Kogan, D.A.; Zhu, S.; Dia, E.Q.; Lu, K.V.; Yoshimoto, K.; Huang, J.H.; Chute, D.J.; et al. Molecular determinants of the response of glioblastomas to EGFR kinase inhibitors. N. Engl. J. Med. 2005, 353, 2012-2024. [CrossRef] [PubMed]

16. Kuan, C.T.; Wikstrand, C.J.; Bigner, D.D. EGF mutant receptor vIII as a molecular target in cancer therapy. Endocr. Relat. Cancer 2001, 8, 83-96. [CrossRef] [PubMed] 
17. Padfield, E.; Ellis, H.P.; Kurian, K.M. Current Therapeutic Advances Targeting EGFR and EGFRvIII in Glioblastoma. Front. Oncol. 2015, 5, 5. [CrossRef] [PubMed]

18. van den Bent, M.J.; Brandes, A.A.; Rampling, R.; Kouwenhoven, M.C.; Kros, J.M.; Carpentier, A.F.; Clement, P.M.; Frenay, M.; Campone, M.; Baurain, J.F.; et al. Randomized phase II trial of erlotinib versus temozolomide or carmustine in recurrent glioblastoma: EORTC brain tumor group study 26034. J. Clin. Oncol. Off. J. Am. Soc. Clin. Oncol. 2009, 27, 1268-1274. [CrossRef]

19. Westphal, M.; Maire, C.L.; Lamszus, K. EGFR as a Target for Glioblastoma Treatment: An Unfulfilled Promise. CNS Drugs 2017, 31, 723-735. [CrossRef]

20. Chakravarti, A.; Wang, M.; Robins, H.I.; Lautenschlaeger, T.; Curran, W.J.; Brachman, D.G.; Schultz, C.J.; Choucair, A.; Dolled-Filhart, M.; Christiansen, J.; et al. RTOG 0211: A phase 1/2 study of radiation therapy with concurrent gefitinib for newly diagnosed glioblastoma patients. Int. J. Radiat. Oncol. Biol. Phys. 2013, 85, 1206-1211. [CrossRef]

21. Rich, J.N.; Reardon, D.A.; Peery, T.; Dowell, J.M.; Quinn, J.A.; Penne, K.L.; Wikstrand, C.J.; Van Duyn, L.B.; Dancey, J.E.; McLendon, R.E.; et al. Phase II trial of gefitinib in recurrent glioblastoma. J. Clin. Oncol. Off. J. Am. Soc. Clin. Oncol. 2004, 22, 133-142. [CrossRef] [PubMed]

22. Janne, P.A.; Yang, J.C.; Kim, D.W.; Planchard, D.; Ohe, Y.; Ramalingam, S.S.; Ahn, M.J.; Kim, S.W.; Su, W.C.; Horn, L.; et al. AZD9291 in EGFR inhibitor-resistant non-small-cell lung cancer. N. Engl. J. Med. 2015, 372, 1689-1699. [CrossRef] [PubMed]

23. Mok, T.S.; Wu, Y.L.; Ahn, M.J.; Garassino, M.C.; Kim, H.R.; Ramalingam, S.S.; Shepherd, F.A.; He, Y.; Akamatsu, H.; Theelen, W.S.; et al. Osimertinib or Platinum-Pemetrexed in EGFR T790M-Positive Lung Cancer. N. Engl. J. Med. 2017, 376, 629-640. [CrossRef] [PubMed]

24. Soria, J.C.; Ohe, Y.; Vansteenkiste, J.; Reungwetwattana, T.; Chewaskulyong, B.; Lee, K.H.; Dechaphunkul, A.; Imamura, F.; Nogami, N.; Kurata, T.; et al. Osimertinib in Untreated EGFR-Mutated Advanced Non-Small-Cell Lung Cancer. N. Engl. J. Med. 2018, 378, 113-125. [CrossRef] [PubMed]

25. Ballard, P.; Yates, J.W.T.; Yang, Z.; Kim, D.W.; Yang, J.C.H.; Cantarini, M.; Pickup, K.; Jordan, A.; Hickey, M.; Grist, M.; et al. Preclinical Comparison of Osimertinib with Other EGFR-TKIs in EGFR-Mutant NSCLC Brain Metastases Models, and Early Evidence of Clinical Brain Metastases Activity. Clin. Cancer Res. 2016, 22, 5130-5140. [CrossRef] [PubMed]

26. Goss, G.; Tsai, C.M.; Shepherd, F.A.; Ahn, M.J.; Bazhenova, L.; Crino, L.; de Marinis, F.; Felip, E.; Morabito, A.; Hodge, R.; et al. CNS response to osimertinib in patients with T790M-positive advanced NSCLC: Pooled data from two phase II trials. Ann. Oncol. 2018, 29, 687-693. [CrossRef]

27. Aladeen, T.; Westphal, E.; Lee, Y.; Rong, C.; Rainka, M.; Capote, H.; McIntyre, R.S. The use of brexpiprazole amongst individuals with insufficient outcomes with aripiprazole or bupropion: A case series. Perspect. Psychiatr. Care 2018, 54, 507-513. [CrossRef]

28. Frankel, J.S.; Schwartz, T.L. Brexpiprazole and cariprazine: Distinguishing two new atypical antipsychotics from the original dopamine stabilizer aripiprazole. Ther. Adv. Psychopharmacol. 2017, 7, 29-41. [CrossRef]

29. Correll, C.U.; Skuban, A.; Ouyang, J.; Hobart, M.; Pfister, S.; McQuade, R.D.; Nyilas, M.; Carson, W.H.; Sanchez, R.; Eriksson, H. Efficacy and Safety of Brexpiprazole for the Treatment of Acute Schizophrenia: A 6-Week Randomized, Double-Blind, Placebo-Controlled Trial. Am. J. Psychiatry 2015, 172, 870-880. [CrossRef]

30. Suzuki, S.; Okada, M.; Kuramoto, K.; Takeda, H.; Sakaki, H.; Watarai, H.; Sanomachi, T.; Seino, S.; Yoshioka, T.; Kitanaka, C. Aripiprazole, an Antipsychotic and Partial Dopamine Agonist, Inhibits Cancer Stem Cells and Reverses Chemoresistance. Anticancer Res. 2016, 36, 5153-5161. [CrossRef]

31. Suzuki, S.; Yamamoto, M.; Togashi, K.; Sanomachi, T.; Sugai, A.; Seino, S.; Yoshioka, T.; Kitanaka, C.; Okada, M. In vitro and in vivo anti-tumor effects of brexpiprazole, a newly-developed serotonin-dopamine activity modulator with an improved safety profile. Oncotarget 2019, 10, 3547-3558. [CrossRef] [PubMed]

32. Okamoto, K.; Okamoto, I.; Hatashita, E.; Kuwata, K.; Yamaguchi, H.; Kita, A.; Yamanaka, K.; Ono, M.; Nakagawa, K. Overcoming Erlotinib Resistance in EGFR Mutation-Positive Non-Small Cell Lung Cancer Cells by Targeting Survivin. Mol. Cancer Ther. 2012, 11, 204-213. [CrossRef] [PubMed]

33. Okamoto, K.; Okamoto, I.; Okamoto, W.; Tanaka, K.; Takezawa, K.; Kuwata, K.; Yamaguchi, H.; Nishio, K.; Nakagawa, K. Role of survivin in EGFR inhibitor-induced apoptosis in non-small cell lung cancers positive for EGFR mutations. Cancer Res. 2010, 70, 10402-10410. [CrossRef] [PubMed] 
34. Morgillo, F.; Woo, J.K.; Kim, E.S.; Hong, W.K.; Lee, H.Y. Heterodimerization of insulin-like growth factor receptor/epidermal growth factor receptor and induction of survivin expression counteract the antitumor action of erlotinib. Cancer Res. 2006, 66, 10100-10111. [CrossRef] [PubMed]

35. Bajetto, A.; Porcile, C.; Pattarozzi, A.; Scotti, L.; Aceto, A.; Daga, A.; Barbieri, F.; Florio, T. Differential role of EGF and BFGF in human GBM-TIC proliferation: Relationship to EGFR-tyrosine kinase inhibitor sensibility. J. Biol. Regul. Homeost. Agents 2013, 27, 143-154. [PubMed]

36. Yamamoto, M.; Suzuki, S.; Togashi, K.; Sanomachi, T.; Seino, S.; Kitanaka, C.; Okada, M. AS602801 Sensitizes Ovarian Cancer Stem Cells to Paclitaxel by Down-regulating MDR1. Anticancer Res. 2019, 39, 609-617. [CrossRef] [PubMed]

37. Dai, C.H.; Shu, Y.; Chen, P.; Wu, J.N.; Zhu, L.H.; Yuan, R.X.; Long, W.G.; Zhu, Y.M.; Li, J. YM155 sensitizes non-small cell lung cancer cells to EGFR-tyrosine kinase inhibitors through the mechanism of autophagy induction. Biochim. Biophys. Acta Mol. Basis Dis. 2018, 1864, 3786-3798. [CrossRef] [PubMed]

38. Wick, W.; Gorlia, T.; Bendszus, M.; Taphoorn, M.; Sahm, F.; Harting, I.; Brandes, A.A.; Taal, W.; Domont, J.; Idbaih, A.; et al. Lomustine and Bevacizumab in Progressive Glioblastoma. N. Engl. J. Med. 2017, 377, 1954-1963. [CrossRef]

39. Gilbert, M.R.; Dignam, J.J.; Armstrong, T.S.; Wefel, J.S.; Blumenthal, D.T.; Vogelbaum, M.A.; Colman, H.; Chakravarti, A.; Pugh, S.; Won, M.; et al. A randomized trial of bevacizumab for newly diagnosed glioblastoma. N. Engl. J. Med. 2014, 370, 699-708. [CrossRef]

40. Cloughesy, T.F.; Cavenee, W.K.; Mischel, P.S. Glioblastoma: From molecular pathology to targeted treatment. Annu. Rev. Pathol. 2014, 9, 1-25. [CrossRef]

41. Pang, L.Y.; Saunders, L.; Argyle, D.J. Epidermal growth factor receptor activity is elevated in glioma cancer stem cells and is required to maintain chemotherapy and radiation resistance. Oncotarget 2017, 8, 72494-72512. [CrossRef]

42. Marie, Y.; Carpentier, A.F.; Omuro, A.M.; Sanson, M.; Thillet, J.; Hoang-Xuan, K.; Delattre, J.Y. EGFR tyrosine kinase domain mutations in human gliomas. Neurology 2005, 64, 1444-1445. [CrossRef] [PubMed]

43. Stommel, J.M.; Kimmelman, A.C.; Ying, H.; Nabioullin, R.; Ponugoti, A.H.; Wiedemeyer, R.; Stegh, A.H.; Bradner, J.E.; Ligon, K.L.; Brennan, C.; et al. Coactivation of receptor tyrosine kinases affects the response of tumor cells to targeted therapies. Science 2007, 318, 287-290. [CrossRef] [PubMed]

44. Bianco, R.; Shin, I.; Ritter, C.A.; Yakes, F.M.; Basso, A.; Rosen, N.; Tsurutani, J.; Dennis, P.A.; Mills, G.B.; Arteaga, C.L. Loss of PTEN/MMAC1/TEP in EGF receptor-expressing tumor cells counteracts the antitumor action of EGFR tyrosine kinase inhibitors. Oncogene 2003, 22, 2812-2822. [CrossRef]

45. Wang, M.Y.; Lu, K.V.; Zhu, S.; Dia, E.Q.; Vivanco, I.; Shackleford, G.M.; Cavenee, W.K.; Mellinghoff, I.K.; Cloughesy, T.F.; Sawyers, C.L.; et al. Mammalian target of rapamycin inhibition promotes response to epidermal growth factor receptor kinase inhibitors in PTEN-deficient and PTEN-intact glioblastoma cells. Cancer Res. 2006, 66, 7864-7869. [CrossRef] [PubMed]

46. Fan, Q.W.; Cheng, C.K.; Nicolaides, T.P.; Hackett, C.S.; Knight, Z.A.; Shokat, K.M.; Weiss, W.A. A dual phosphoinositide-3-kinase alpha/mTOR inhibitor cooperates with blockade of epidermal growth factor receptor in PTEN-mutant glioma. Cancer Res. 2007, 67, 7960-7965. [CrossRef] [PubMed]

47. Gallego, O.; Cuatrecasas, M.; Benavides, M.; Segura, P.P.; Berrocal, A.; Erill, N.; Colomer, A.; Quintana, M.J.; Balaña, C.; Gil, M.; et al. Efficacy of erlotinib in patients with relapsed gliobastoma multiforme who expressed EGFRVIII and PTEN determined by immunohistochemistry. J. Neuro-Oncol. 2013, 116, 413-419. [CrossRef]

48. De Groot, J.F.; Gilbert, M.R.; Aldape, K.; Hess, K.R.; Hanna, T.A.; Ictech, S.; Groves, M.D.; Conrad, C.; Colman, H.; Puduvalli, V.K.; et al. Phase II study of carboplatin and erlotinib (Tarceva, OSI-774) in patients with recurrent glioblastoma. J. Neuro-Oncol. 2008, 90, 89-97. [CrossRef]

49. Reardon, D.A.; Desjardins, A.; Vredenburgh, J.J.; Gururangan, S.; Friedman, A.H.; Herndon, J.E., 2nd; Marcello, J.; Norfleet, J.A.; McLendon, R.E.; Sampson, J.H.; et al. Phase 2 trial of erlotinib plus sirolimus in adults with recurrent glioblastoma. J. Neuro-Oncol. 2010, 96, 219-230. [CrossRef] [PubMed]

50. Akhavan, D.; Pourzia, A.L.; Nourian, A.A.; Williams, K.J.; Nathanson, D.; Babic, I.; Villa, G.R.; Tanaka, K.; Nael, A.; Yang, H.; et al. De-repression of PDGFRbeta transcription promotes acquired resistance to EGFR tyrosine kinase inhibitors in glioblastoma patients. Cancer Discov. 2013, 3, 534-547. [CrossRef]

51. Iwanami, A.; Gini, B.; Zanca, C.; Matsutani, T.; Assuncao, A.; Nael, A.; Dang, J.; Yang, H.; Zhu, S.; Kohyama, J.; et al. PML mediates glioblastoma resistance to mammalian target of rapamycin (mTOR)-targeted therapies. Proc. Natl. Acad. Sci. USA 2013, 110, 4339-4344. [CrossRef] [PubMed] 
52. Li, J.; Zhu, S.; Kozono, D.; Ng, K.; Futalan, D.; Shen, Y.; Akers, J.C.; Steed, T.; Kushwaha, D.; Schlabach, M.; et al. Genome-wide shRNA screen revealed integrated mitogenic signaling between dopamine receptor D2 (DRD2) and epidermal growth factor receptor (EGFR) in glioblastoma. Oncotarget 2014, 5, 882-893. [CrossRef] [PubMed]

53. Clemens, M.R.; Gladkov, O.A.; Gartner, E.; Vladimirov, V.; Crown, J.; Steinberg, J.; Jie, F.; Keating, A. Phase II, multicenter, open-label, randomized study of YM155 plus docetaxel as first-line treatment in patients with HER2-negative metastatic breast cancer. Breast Cancer Res. Treat. 2015, 149, 171-179. [CrossRef] [PubMed]

54. Kelly, R.J.; Thomas, A.; Rajan, A.; Chun, G.; Lopez-Chavez, A.; Szabo, E.; Spencer, S.; Carter, C.A.; Guha, U.; Khozin, S.; et al. A phase I/II study of sepantronium bromide (YM155, survivin suppressor) with paclitaxel and carboplatin in patients with advanced non-small-cell lung cancer. Ann. Oncol. 2013, 24, 2601-2606. [CrossRef]

55. Kudchadkar, R.; Ernst, S.; Chmielowski, B.; Redman, B.G.; Steinberg, J.; Keating, A.; Jie, F.; Chen, C.; Gonzalez, R.; Weber, J. A phase 2, multicenter, open-label study of sepantronium bromide (YM155) plus docetaxel in patients with stage III (unresectable) or stage IV melanoma. Cancer Med. 2015, 4, 643-650. [CrossRef] [PubMed]

56. Citrome, L.; Ota, A.; Nagamizu, K.; Perry, P.; Weiller, E.; Baker, R.A. The effect of brexpiprazole (OPC-34712) and aripiprazole in adult patients with acute schizophrenia: Results from a randomized, exploratory study. Int. Clin. Psychopharmacol. 2016, 31, 192-201. [CrossRef] [PubMed]

57. Parikh, N.B.; Robinson, D.M.; Clayton, A.H. Clinical role of brexpiprazole in depression and schizophrenia. Ther. Clin. Risk Manag. 2017, 13, 299-306. [CrossRef]

58. Stahl, S.M. Mechanism of action of brexpiprazole: Comparison with aripiprazole. CNS Spectr. 2016, 21, 1-6. [CrossRef]

59. Citrome, L. The ABC's of dopamine receptor partial agonists-Aripiprazole, brexpiprazole and cariprazine: The 15-min challenge to sort these agents out. Int. J. Clin. Pract. 2015, 69, 1211-1220. [CrossRef]

60. Matsuda, K.; Sato, A.; Okada, M.; Shibuya, K.; Seino, S.; Suzuki, K.; Watanabe, E.; Narita, Y.; Shibui, S.; Kayama, T.; et al. Targeting JNK for therapeutic depletion of stem-like glioblastoma cells. Sci. Rep. 2012, 2, 516. [CrossRef]

61. Sato, A.; Sunayama, J.; Matsuda, K.; Seino, S.; Suzuki, K.; Watanabe, E.; Tachibana, K.; Tomiyama, A.; Kayama, T.; Kitanaka, C. MEK-ERK signaling dictates DNA-repair gene MGMT expression and temozolomide resistance of stem-like glioblastoma cells via the MDM2-p53 axis. Stem Cells 2011, 29, 1942-1951. [CrossRef] [PubMed]

62. Sunayama, J.; Matsuda, K.; Sato, A.; Tachibana, K.; Suzuki, K.; Narita, Y.; Shibui, S.; Sakurada, K.; Kayama, T.; Tomiyama, A.; et al. Crosstalk between the PI3K/mTOR and MEK/ERK pathways involved in the maintenance of self-renewal and tumorigenicity of glioblastoma stem-like cells. Stem Cells 2010, 28, 1930-1939. [CrossRef] [PubMed]

63. Togashi, K.; Okada, M.; Yamamoto, M.; Suzuki, S.; Sanomachi, T.; Seino, S.; Yamashita, H.; Kitanaka, C. A Small-molecule Kinase Inhibitor, CEP-1347, Inhibits Survivin Expression and Sensitizes Ovarian Cancer Stem Cells to Paclitaxel. Anticancer Res. 2018, 38, 4535-4542. [CrossRef] [PubMed]

64. Suzuki, S.; Okada, M.; Shibuya, K.; Seino, M.; Sato, A.; Takeda, H.; Seino, S.; Yoshioka, T.; Kitanaka, C. JNK suppression of chemotherapeutic agents-induced ROS confers chemoresistance on pancreatic cancer stem cells. Oncotarget 2015, 6, 458-470. [CrossRef] [PubMed]

(C) 2019 by the authors. Licensee MDPI, Basel, Switzerland. This article is an open access article distributed under the terms and conditions of the Creative Commons Attribution (CC BY) license (http://creativecommons.org/licenses/by/4.0/). 